\title{
NUEVOS CAMINOS EN LA INVESTIGACIÓN DEL GLAUCOMA
}

\section{NEW DIRECTIONS IN GLAUCOMA RESEARCH}

\author{
SHARMA SC ${ }^{1}$
}

En el glaucoma inducido experimentalmente en el laboratorio, no todas las células ganglionares de la retina (CGR) mueren al mismo tiempo. Por el contrario, el proceso tiene lugar a lo largo de varios meses. Por ello es posible estudiar en diferentes momentos, a lo largo de la progresión de esta neuropatía óptica, el estado de las células que todavía viven y evitar su muerte. La señal de muerte celular por apoptosis o bien no es recibida al mismo tiempo por todas las CGR o bien cada célula responde de forma diferente en los ojos con glaucoma. La muerte de las CGR ocurre por efecto directo del proceso patológico primario y además puede ser secundaria al efecto que la muerte de las propias CGR ejerce sobre otras CGR adyacentes lesionadas. Dentro de los estímulos específicos de apoptosis en glaucoma se incluyen el bloqueo del transporte axonal y el bloqueo de la depleción de neurotrofinas, la excitotoxicidad por glutamato, los anticuerpos anti-proteínas de shock y la regulación de la óxido nítrico sintetasa con la formación de oxígeno reactivo. En la retina del primate, tras la pérdida de CGR se produce una atrofia progresiva de las células supervivientes que conduce a la disfunción visual. Los cambios transneuronales en los primates con glaucoma llevan a la pérdida y a la reducción del tamaño de algunas células del núcleo geniculado lateral (NGL), la diana de los axones ópticos. La evaluación funcional de los cambios visuales en los pacientes con glaucoma utilizando resonancia magnética nuclear (RMN) mostró una pérdida de función visual que se correlaciona claramente con la pérdida de campo visual en el ojo (Duncan et al.) (1). ¿Puede este método evaluar los cambios en los estadios iniciales del glaucoma antes de que ocurra la muerte de las CGR? Los estudios con RMN funcional en pacientes con degeneración macular con pérdida de visión foveal muestran extensa actividad en el área foveal cortical (Baker et al.) (2) y apuntan a una extensa reorganización en las áreas terminales de visión. Es razonable suponer que en la degeneración macular algunas células retinianas foveales sobreviven y que éstas CGR expanden sus proyecciones en el córtex o que axones de CGR parafoveales invaden el territorio del área foveal del córtex. En las ratas con glaucoma (King et al.) (3), el escotoma visual no es aparente en el tectum (área terminal de los axones ópticos) en estadios iniciales; la detección de áreas sensitivas de mayor tamaño en la periferia es el signo precoz de alteración geométrica de la retina. Suponemos que tras la muerte de las células de mayor tamaño de la periferia, las células ganglionares que quedan extienden sus axones hacia el tectum conduciendo a un aumento de las áreas receptivas. $\mathrm{La}$ relación entre la duración y la magnitud de la elevación de la presión intraocular (PIO) muestra una correlación positiva significativa con los porcentajes de los tamaños de las áreas receptivas en el tectum en las ratas con glaucoma. Esta correlación se hizo evidente después de 6 meses de elevación mantenida de la PIO. Un mayor aumento en el tamaño del área visual sensitiva se correlaciona muy bien con aumentos de la PIO. Un aumento en el área visual sensitiva podría representar un efecto muy a largo plazo de las CGR restantes en el que

\footnotetext{
1 S.C. Sharma MD, PhD. Catedrático de Oftalmología y Biología Celular. Departamento de Oftalmología. New York Medical College, Valhalla, Nueva York, EEUU.

E-mail: SANSAR_SHARMA@NYMC.EDU
}

El Prof. Sharma ha llevado a cabo avances revolucionarios en el campo del glaucoma experimental. Creó el primer modelo de glaucoma en ratas que hasta el momento es el método más utilizado para la cauterización de venas epiesclerales. Describió por primera vez la muerte de las CGR por apoptosis en el glaucoma y tiene publicados muchos artículos sobre el mecanismo de muerte celular y la supervivencia de las CGR en el glaucoma. 
sus axones tratan de compensar la pérdida de las áreas ocupando un territorio terminal mayor del habitual (King et al.) (3). En el glaucoma del primate, la muerte de las CGR lleva a cambios en el núcleo geniculado lateral y el VII donde se han descrito muerte celular y contracción del NGL (Yucel et al.) (4). La actividad de la citocromo oxidasa disminuye en las columnas dominantes oculares correspondientes al ojo con glaucoma. Estos cambios en los animales con glaucoma llevaron a los autores a definir el glaucoma como una enfermedad neurodegenerativa. Hasta ahora, es evidente que el inicio de la elevación de la PIO desencadena cambios en la retina así como en los centros diana del sistema nervioso central cuyo efecto continúa durante mucho tiempo.

Todavía está por resolver el continuo debate en el «dogma» del glaucoma sobre si mueren primero las CGR o si son los axones los primeros en dañarse. En ambas situaciones los cambios comienzan en los núcleos terminales de las vías visuales. El dramático cambio detectado en los centros visuales en animales con glaucoma plantea la cuestión de si la relación funcional entre la pérdida o degradación del campo visual y los cambios en la agudeza visual y los umbrales de visión debe ser estudiada. La capacidad del sistema neuronal para remodelarse y repararse después de una lesión se ve influida por interacciones entre las CGR viables restantes en la retina glaucomatosa así como por la respuesta de células individuales a la reducción de la PIO y a la administración de agentes neuroprotectores. Si reduciendo la PIO y/o administrando agentes neu- roprotectores se pudiera determinar las consecuencias funcionales en la retina que llevan a una restitución parcial o completa de la función, esto podría ofrecer un nuevo camino para la mejoría de función visual en pacientes con glaucoma. ¿Hay una reorganización funcional en el córtex visual primario en humanos en respuesta al glaucoma? Si la aparición de una pérdida del campo visual exige unos meses de elevación mantenida de la PIO en ratas y ocurre cuando la cascada de muerte de CGR se ha reducido, podría llevar mucho más tiempo en humanos donde la PIO en ojos con glaucoma ha sido controlada. Tratar los centros visuales con agentes neuroprotectores para reducir o controlar la muerte de las neuronas del CGL y de la corteza podría beneficiar a los pacientes con glaucoma.

\section{BIBLIOGRAFÍA}

1. Duncan RO, Sample PA, Weinreb RW, Bowd C, Zangwill LM. Retinotopic organization of primary visual cortex in glaucoma. Comparing fMRI measurements of cortical function with visual loss. Prog Retin Eye Res 2007; 26: 38-56.

2. Baker CI, Peli E, Knouf N, Kanwisher NG. Reorganization of visual processing in macular degeneration. J Neuroscience 2005; 25: 614-618.

3. King WM, Sarup V, Sauve Carpenter DO, Sharma SC. Expansion of visual receptive fields in glaucomatous rat. Visual Neurosci 2006; 23: 137-142.

4. Yucel YH, Zhang Q, Weinreb RN, Kaufman PL, Gupta N. Effects of retinal ganglion cell loss on Magno-, ParvoKonicellular pathways in the lateral geniculate nucleus and the visual cortex in glaucoma. Prog Retin Eye Res 2003; 22 : 465-481. 